Journal of Infection Control

Elsevier Editorial System(tm) for American

Manuscript Draft

Manuscript Number: AJIC-D-18-00056R2

Title: Adenovirus pseudo-outbreak in a large UK neonatal intensive care unit

Article Type: Brief Report

Keywords: Adenovirus; pseudo-outbreak; neonatal; NICU; stool antigen test; Rotavirus-Adenovirus Combi test

Corresponding Author: Dr. Nick Keith Jones, MBBS

Corresponding Author's Institution: Cambridge University Hospitals NHS Foundation Trust

First Author: Nick Keith Jones, MBBS

Order of Authors: Nick Keith Jones, MBBS; Kyriaki Ranellou, MD, PhD; Hongyi Zhang, MBBS, PhD; Hamid Jalal, MA, MSC, MBBS, PhD

Abstract: An unusually high number of positive adenovirus stool antigen tests were observed in neonatal samples from a large tertiary referral unit over a 10-week period, prompting the declaration of an outbreak and escalation of infection control precautions accordingly. Subsequent testing of original samples by alternative methods revealed a series of false-positive results. This is the first adenovirus pseudo-outbreak to be reported in the United Kingdom, and the first using the Proflow ${ }^{\mathrm{TM}}$ Rotavirus-Adenovirus Combi test. 
Response to Reviewers

Dear Editors,

Please find attached out revised manuscript, which is inclusive of the revisions that you suggested.

Please note, we have now received the rotavirus PCR result that we had been waiting for when we sent our last correspondence. This came back as weakly positive for wild-type rotavirus (1 of 2 confirmation assays positive, as is described in the results section of the manuscript). 


\title{
Adenovirus pseudo-outbreak in a large UK neonatal intensive care unit
}

\author{
Dr. Nick K Jones ${ }^{\mathrm{a}, \mathrm{b}} \mathrm{MBBS}, \mathrm{MRCP}(\mathrm{UK})$ \\ Dr. Kyriaki Ranellou ${ }^{a, c} \mathrm{MD}, \mathrm{PhD}$ \\ Dr. Hongyi Zhang ${ }^{a}$ MBBS, PhD, FRCPath \\ Dr. Hamid Jalal ${ }^{\mathrm{a}}$ MA, MSc, MBBS, FRCPath, PhD, DHSM
}

${ }^{a}$ Cambridge Clinical Microbiology and Public Health Laboratory, Department of Clinical Virology, CMPHL level 6, Addenbrooke's Hospital, Box 236, Cambridge, UK

${ }^{b}$ University of Cambridge Department of Medicine, Addenbrooke's Hospital, Box 157, Cambridge, UK

' University of Cambridge Department of Pathology, Division of Virology, Addenbrooke's Hospital, Cambridge, UK

Correspondence: Dr. Nick K Jones, Department of Clinical Virology, Box 236, Cambridge University Hospitals NHS Foundation Trust, Hills Road, Cambridge, CB2 OQW

nicholas.jones@addenbrookes.nhs.uk_Telephone: UK (+44)7940039343

kyriaki.ranellou@addenbrookes.nhs.uk

hongyi.zhang@addnebrookes.nhs.uk

hamid.jalal@addenbrookes.nhs.uk 


\section{Adenovirus pseudo-outbreak in a large UK neonatal intensive care unit}

\section{ABSTRACT}

An unusually high number of positive adenovirus stool antigen tests were observed in neonatal samples from a large tertiary referral unit over a 10-week period, prompting the declaration of an outbreak and escalation of infection control precautions accordingly. Subsequent testing of original samples by alternative methods revealed a series of false-positive results. This is the first adenovirus pseudooutbreak to be reported in the United Kingdom, and the first using the Proflow ${ }^{\mathrm{TM}}$ Rotavirus-Adenovirus Combi test. 
Highlights

- A series of false-positive results led to incorrect reporting of an outbreak.

- Infection control precautions were unnecessarily escalated.

- Retrospective testing by alternative means revealed the problem.

- Pseudo-outbreaks cause unnecessary cost to hospitals and laboratories.

- Early identification and investigation is imperative to minimise disruption. 


\section{Adenovirus pseudo-outbreak in a large}

UK neonatal intensive care unit 


\section{ABSTRACT}

An unusually high number of positive adenovirus stool antigen tests were observed in neonatal samples from a large tertiary referral unit over a 10-week period, prompting the declaration of an outbreak and escalation of infection control precautions accordingly. Subsequent testing of original samples by alternative methods revealed a series of false-positive results. This is the first adenovirus pseudooutbreak to be reported in the United Kingdom, and the first using the Proflow ${ }^{\mathrm{TM}}$ Rotavirus-Adenovirus Combi test.

Keywords: adenovirus; pseudo-outbreak; neonatal; NICU; stool antigen test; Rotavirus-Adenovirus Combi test

\section{BACKGROUND}

Adenovirus infection is a common cause of gastroenteritis in children, making it an important consideration in the diagnostic processing of paediatric diarrhoeal stool specimens ${ }^{1}$. Adenoviruses may be shed for months after initial infection ${ }^{2,3}$, are highly resistant to physical and chemical cleaning ${ }^{4}$, and remain stable at room temperature for prolonged periods in fomites ${ }^{4}$, making them a particular infection control challenge. While enteric infection rarely causes systemic disease in the immunocompetent, neonates and the immunocompromised can develop disseminated infection, which carries high risk of morbidity and mortality ${ }^{4,5,6}$. 
The Proflow ${ }^{\mathrm{TM}}$ Rotavirus-Adenovirus Combi test is a single-use rapid membrane immunoassay for the qualitative detection of rotavirus and adenovirus antigens in faeces. The manufacturers report both sensitivity and specificity of $>99 \%$ when compared to results of another commercially available adenovirus antigen immunochromatographic membrane assay ${ }^{7}$, but no comparisons with alternative testing methods are available. There is also reportedly no known cross-reactivity to astrovirus, Escherichia coli, Campylobacter spp., Giardia lamblia, or human haemaglobin ${ }^{7}$.

From $31^{\text {st }}$ July to $8^{\text {th }}$ October 2017,12 stool specimens from 6 neonatal intensive care patients tested positive for adenovirus antigen, prompting the declaration of an outbreak. Here, we describe the process of discovery of a pseudo-outbreak due to a series of false-positive results, and how a look-back through previously reported results revealed a much larger-scale problem. Neonatal pseudo-outbreaks of adenovirus and rotavirus have previously been reported $^{8,9}$, but this is the first UK adenovirus pseudooutbreak, and the first arising from the Proflow ${ }^{\mathrm{TM}}$ Rotavirus-Adenovirus Combi.

\section{MATERIALS AND METHODS}

\section{Hospital setting}

Addenbrooke's Hospital is a 1000-bedded teaching hospital in the East of England that serves a large geographical area. The Neonatal Intensive Care Unit has capacity for 40 critically ill patients and frequently cares for neonates with complex medical and surgical needs, and those born at $<28$ weeks gestation. 


\section{Antigen testing}

Adenovirus antigen testing was performed using the Proflow ${ }^{\mathrm{TM}}$ Rotavirus-Adenovirus Combi test, in accordance with manufacturer's instructions ${ }^{7}$. Kit-provided negative and positive controls were run with each batch of tests, with no control failure identified. Stool samples were collected in universal containers and tested within 12 hours of sample receipt.

\section{Polymerase chain reaction (PCR)}

Adenovirus PCR was performed using an in-house assay that targets a pan-specific region of the hexon gene, with a lower limit of detection of 2 copies/ml (95\% CL 1.6-4.3) using adenovirus type 2 DNA (Cat. No. 15270-010; Life Technologies). The assay has long been in routine use for blood, respiratory, and cerebrospinal fluid samples, and was validated for stool specimens by comparing serial log dilutions of a high concentration of adenovirus in phosphate-buffered saline and $10 \%$ faecal suspension. This demonstrated a linear relationship between cycle threshold value and log dilution ( $R 2$ value of 0.984 ). DNA extraction was performed using QIAGEN’s QIAsymphony ${ }^{\circledR}$ DSP virus/pathogen mini extraction kit, following a mechanical bead-beating step. Positive and negative controls were included in each run, as was a pre-extraction internal control for identifying incomplete DNA extraction and inhibitors of amplification.

\section{Clinical and test data extraction}

Suspected outbreak results were collated prospectively. Clinical data and historical testing data were extracted using the hospital's electronic health records system. 


\section{RESULTS}

Concerns of an adenovirus outbreak arose on 9th September 2017, following five positive antigen tests from three patients in shared clinical areas. Enhanced infection control measures, including departmental deep cleaning and the use of gloves and aprons for routine care, were implemented from 11th September. Between then and 13th October, a further two samples from these patients, plus five samples from three additional patients, tested positive (figure 1). This triggered further deep cleaning, and screening of asymptomatic contacts. Table 1 shows the clinical characteristics of suspected outbreak cases, all of whom were born preterm with low, very low, or extremely low birth weight. For each of the symptomatic neonates, common enteric bacterial pathogens were excluded by routine stool culture on xylose-lysine-deoxycholate (XLD), cefixime-tellurite-sorbitol-MacConkey (CT-SMAC), and charcoal-cefoperazone-deoxycholate (CCDA) agars. Staining for cryptosporidium was also performed as a matter of routine. In view of the emergence of new cases of detectable adenovirus antigen despite escalated infection control precautions, a pseudo-outbreak was suspected. Eleven of 12 positive samples from the six 'outbreak' cases, and 13 of 14 positive screening samples from 29 asymptomatic contacts, were retrieved from storage for re-testing. Sixteen of these samples underwent repeat Rotavirus-Adenovirus Combi testing, which gave $81.3 \%$ agreement with the initial results $(13 / 16)$. However, none of the 24 samples that were re-tested by PCR gave a positive result. In light of this, the situation was revised to that of a pseudo-outbreak on 19th October and standard infection control practices resumed.

Norovirus infection was retrospectively excluded by validated in-house PCR on one original stool sample from each of the symptomatic neonates. The five neonates for which there was sufficient stool sample remaining were retrospectively tested for rotavirus at the national reference laboratory. Rotavirus PCR 
revealed one case of detectable rotavirus that was characterised as wild-type in one of two confirmation assays (Patient E), and one case of detectable vaccine-strain rotavirus in a neonate that had received ROTARIX vaccination ten days prior to sample collection (Patient F). Other common bacterial, parasitic, and viral causes of gastroenteritis were excluded by a twenty five pathogen TaqMan Array Card (Applied Biosystems, Foster City, CA) assay, using stored nucleic acid from each original stool sample. It must be acknowledged, however, that this assay is not yet validated for clinical use.

\section{Re-evaluation of past tests}

A look back exercise of all adenovirus antigen tests performed between $1^{\text {st }}$ August and $19^{\text {th }}$ October 2017 revealed that of 643 samples tested, 204 (31.7\%) had been reported positive. These involved tests from two separate Proflow ${ }^{\mathrm{TM}}$ Rotavirus-Adenovirus Combi kits. Seventy-six of the 204 samples reported positive were recovered from storage for re-testing with PCR. Of these, 12 (15.8\%) were positive, 62 (81.6\%) were negative, and two (2.6\%) gave invalid results due to internal control failure. The Medicines and Healthcare products Regulatory Agency (MHRA) were informed of these investigation findings, and the Proflow ${ }^{\mathrm{TM}}$ Rotavirus-Adenovirus Combi test was subsequently withdrawn from sale in the United Kingdom and replaced by the Proflow ${ }^{\mathrm{TM}}$ Rotavirus-Adenovirus Dual Test. This replacement product, which has a modified display for presenting positive results, uses identical antibodies, diluent, and test method to the Rotavirus-Adenovirus Combi. In response to this pseudo-outbreak investigation, our laboratory has adjusted its algorithm for the routine detection of adenovirus in stool to include the use of in-house PCR. 
Figure 1. Timeline of positive adenovirus antigen tests on stool specimens from symptomatic neonates on the Neonatal Intensive Care Unit (NICU)

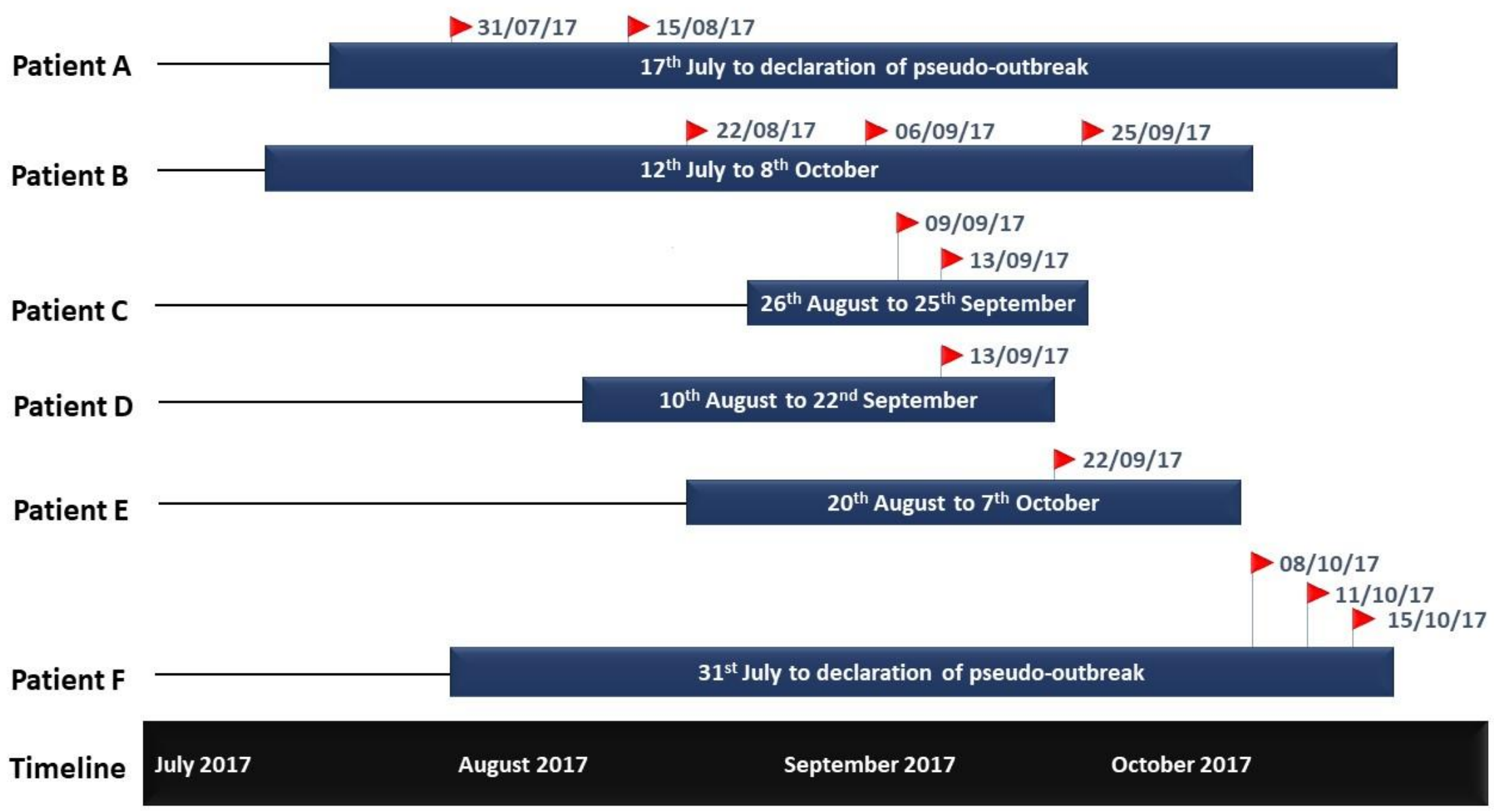


Table 1. Clinical characteristics of pseudo-outbreak cases

\begin{tabular}{|c|c|c|c|c|c|c|}
\hline Characteristic & Patient A & Patient B & Patient C & Patient D & Patient E & Patient F \\
\hline $\begin{array}{l}\text { Chronological age } \\
\text { (days) }\end{array}$ & 14 & 39 & 12 & 33 & 31 & 74 \\
\hline $\begin{array}{l}\text { Gestational age } \\
\text { (weeks + days) }\end{array}$ & $23+5$ & $34+1$ & $26+5$ & $31+0$ & $24+1$ & $31+2$ \\
\hline Sex & $M$ & $\mathrm{~F}$ & $\mathrm{~F}$ & $M$ & $M$ & $M$ \\
\hline $\begin{array}{l}\text { Birth weight } \\
\text { (grams) }\end{array}$ & 665 & 2050 & 930 & 1200 & 391 & 1730 \\
\hline $\begin{array}{l}\text { Description of } \\
\text { stool }\end{array}$ & Watery & $\begin{array}{l}\text { Loose } \\
\text { Light brown }\end{array}$ & $\begin{array}{l}\text { Offensive } \\
\text { Yellow }\end{array}$ & Watery & Watery & Watery \\
\hline $\begin{array}{l}\text { Number of } \\
\text { positive antigen } \\
\text { tests }\end{array}$ & 2 & 3 & 2 & 1 & 1 & 3 \\
\hline $\begin{array}{l}\text { Concurrent } \\
\text { infections }\end{array}$ & $\begin{array}{l}\text { Staphylococcus } \\
\text { haemolyticus }\end{array}$ & Nil & $\begin{array}{l}\text { Staphylococcus } \\
\text { aureus }\end{array}$ & Nil & $\begin{array}{l}\text { Serratia } \\
\text { marcescens }\end{array}$ & $\begin{array}{l}\text { Staphylococcus } \\
\text { aureus } \\
\text { Rhinovirus }\end{array}$ \\
\hline $\begin{array}{l}\text { Co-morbidity at } \\
\text { the time of first } \\
\text { positive }\end{array}$ & $\begin{array}{l}\text { Sepsis } \\
\text { RDS* } \\
\text { PDA }^{+} \\
\text {Anaemia }\end{array}$ & $\begin{array}{l}\text { Oesophageal } \\
\text { atresia } \\
\text { Gastrostomy } \\
\text { Dextrocardia } \\
\text { Absent right } \\
\text { lung }\end{array}$ & $\begin{array}{l}\text { Sepsis } \\
\text { Jaundice } \\
\text { Metabolic } \\
\text { acidosis }\end{array}$ & $\begin{array}{l}\text { Sepsis } \\
\text { RDS* } \\
\text { Jaundice }\end{array}$ & $\begin{array}{l}\text { Sepsis } \\
\text { RDS* }^{*} \\
\text { PDA }^{+} \\
\text {Dysplastic } \\
\text { aortic valve } \\
\text { Jaundice } \\
\text { Necrosis of } \\
\text { small toe }\end{array}$ & $\begin{array}{l}\text { RDS* } \\
\text { Bilateral } \\
\text { congenital } \\
\text { talipes } \\
\text { equinovarus } \\
\text { deformity }\end{array}$ \\
\hline
\end{tabular}

\section{CONCLUSIONS}

The cause of assay false-reactivity that led to this pseudo-outbreak remains unclear; exhaustive investigation of the underlying mechanism of test failure is beyond the scope of this report, but should be undertaken by Pro-Lab Diagnostics, in liaison with the MHRA. There are inherent differences in the constituents of neonatal and adult stools, arising from dietary and environmental factors, as well as 
differences in the microbiome ${ }^{10}$. These differences could provide potential explanations for the higher false-positivity rate among this cohort of neonatal patients (100\%) compared to the overall falsepositivity rate of all samples included in the look back exercise (81.6\%). While likely alternative causes of infective gastroenteritis were excluded by routine and experimental methods for each of these suspected outbreak patients, potential extraintestinal and non-infective explanations for their loose stools remain. The 2009 National Institute for Health and Care Excellence (NICE) Diarrhoea and Vomiting Caused by Gastroenteritis: Diagnosis, Assessment and Management in Children Younger than 5 Years guidelines (Clinical Guideline: CG84) highlight non-enteric infections, surgical or inflammatory bowel conditions, and drug-induced diarrhoea as important considerations in patients presenting with loose stools ${ }^{11}$. They also state that "Children younger than 12-18 months commonly present with non-specific symptoms and signs of non-enteric infections and non-infective gastrointestinal disorders". All of the patients involved in this pseudo-outbreak were on broad spectrum antibiotic therapy, which could account for their altered bowel habit. Additional potential causes of diarrhoea can be identified as follows: Patient A had sepsis; Patient B had a functioning gastrostomy in situ; Patient $\mathrm{C}$ had sepsis and jaundice; Patient D had sepsis and jaundice; Patient E had sepsis and jaundice (Table 1).

This pseudo-outbreak serves as a stark reminder of the need for caution when interpreting a high incidence of positive results from a microbiological test. In this instance, the mislabelling of falsepositive results as an infectious outbreak led to significant cost through unnecessary infection control measures and repeat testing of samples, as well as damage to the reputation of the laboratory and hospital, and avoidable anxiety for the relatives of neonates wrongly labelled as infected. Future clusters of results suspicious for false-positivity should be scrutinised by alternative testing methods at the earliest possible opportunity. 


\section{ACKNOWLEDGEMENTS}

We thank the staff of the Neonatal Intensive Care Unit and the Infection Control team at Addenbrooke's Hospital for their excellent work in ensuring timely and appropriate escalation of infection control measures in response to this suspected outbreak. We also thank the relatives of patients directly and indirectly involved in the pseudo-outbreak for their patience during periods of diagnostic uncertainty. Finally, we thank the staff of the Cambridge Microbiology and Public Health Laboratory for their help in confirming the pseudo-outbreak through identifying and re-testing archived samples. In particular, $\mathrm{Dr}$ Surendra Parmar, Martin Strickland, and Emma Heasman-Hunt.

\section{REFERENCES}

1. Uhnoo I, Wadell G, Svensson L, Johansson ME. Importance of enteric adenoviruses 40 and 41 in acute gastroenteritis in infants and young children. J Clin Microbiol. 1984;20(3):365-72.

2. Fox JP, Brandt CD, Wassermann FE, Hall CE, Spigland I, Kogon A, et al. The virus watch program: a continuing surveillance of viral infections in metropolitan New York families. VI. Observations of adenovirus infections: virus excretion patterns, antibody response, efficiency of surveillance, patterns of infections, and relation to illness. Am J Epidemiol. 1969;89(1):25-50.

3. Fox JP, Hall CE, Cooney MK. The Seattle Virus Watch. VII. Observations of adenovirus infections. Am J Epidemiol. 1977;105(4):362-86.

4. Echavarria M. Adenoviruses in immunocompromised hosts. Clin Microbiol Rev. 2008;21(4):70415. 
5. Pham TT, Burchette JL, Hale LP. Fatal disseminated adenovirus infections in immunocompromised patients. Am J Clin Pathol. 2003;120(4):575-83.

6. Abzug MJ, Levin MJ. Neonatal adenovirus infection: four patients and review of the literature. Pediatrics. 1991;87(6):890-6.

7. Pro-lab diagnostics. Proflow ${ }^{\mathrm{TM}}$ Rotavirus-Adenovirus Combi product insert. 2013.

8. Faden H, Ramani R, Lamson D, St George K. Pseudo-outbreak of adenovirus infection in a neonatal intensive care unit due to a false-positive antigen detection test. J Clin Microbiol. 2010;48(11):4251-2.

9. Tan BF, Chen YC, Lee CN, Chang LY, Hsieh WS, Tsao PN, et al. Pseudo-outbreak of rotavirus infection in a neonatal intensive care unit. J Microbiol Immunol Infect. 2016;49(6):947-54.

10. Gritz E, Bhandari V. The Human Neonatal Gut Microbiome: A Brief Review. Frontiers in Pediatrics. 2015;3.

11. National Collaborating Centre for Women's and Children's Health (UK). Diarrhoea and Vomiting Caused by Gastroenteritis: Diagnosis, Assessment and Management in Children Younger than 5 Years. London: RCOG Press; 2009 Apr. (NICE Clinical Guidelines, No. 84.) 3, Diagnosis. 
${ }^{*}$ Conflict of Interest Form

Click here to download Conflict of Interest Form: COI disclosure form - Nick K Jones.pdf 
${ }^{*}$ Conflict of Interest Form

Click here to download Conflict of Interest Form: COI disclosure form - Kyriaki Ranellou.pdf 
${ }^{\star}$ Conflict of Interest Form

Click here to download Conflict of Interest Form: COI disclosure form - Hongyi Zhang.pdf 
${ }^{\star}$ Conflict of Interest Form

Click here to download Conflict of Interest Form: COI disclosure form - Hamid Jalal.pdf 